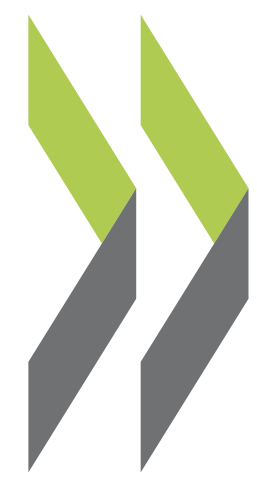

PEB Exchange, Programme on Educational Building 2006/08

\title{
Design Quality Indicator for Schools in the United OECD 


\section{Design Quality Indicator for Schools in the United Kingdom}

In December 2005, the United Kingdom launched a process for evaluating the design quality of primary and secondary school buildings. The Design Quality Indicator (DQI) for Schools is a tool that can assist stakeholders - teachers, parents, school governors, students, community members, local authority clients and building professionals - to achieve design excellence in new or refurbished school buildings and grounds. The DQI framework was developed by the Department for Education and Skills and the Construction Industry Council.

Four versions of the Design Quality Indicators for Schools correspond to different stages of the building's life cycle:

- At the initial (consultation) phase, the tool is used by a group of key demand side stakeholders to facilitate a consensus on priorities and ambitions for the design brief.

- At the mid-design phase, the tool is used by supply and demand stakeholders to assess how well plans for the building have met the objectives set at the initial stage, and to make adjustments accordingly.

- At the ready-for-occupation stage, the tool is used to check whether the design brief and original objectives have been achieved at occupation.

- At the in-use stage, the tool is used to process feedback from the project team and building users to improve current and future projects.

The DQI for Schools measures design quality according to three criteria:

- Functionality. The building should provide access for all and space for teaching and non-teaching activities, and should adapt to changing needs.

- Build quality. The building's finishes should be durable; design should minimise the requirements for mechanical ventilation, cooling and heating; and the layout, structure and engineering systems should be well integrated, using sustainable materials and systems.

- Impact. The building should be well sited and display character and innovation; forms and materials should be well detailed; and the facility should contain pleasant circulation spaces, common areas and natural light.

Involving building users not only serves to improve the design quality of the school, it also creates a sense of shared ownership and identity and can have a positive impact on student performance. The Design Quality Indicator for Schools evaluation process involves a range of supply and demand stakeholders. A trained DQI facilitator asks these respondents about their aspirations for the school, and about their thoughts on the completed school building or design. 


\section{Case study ${ }^{1}$ - Parliament Hill School, London Borough of Camden Description}

Parliament Hill School is situated in Highgate, London. The school used the DQI as part of a "trailblazer" project, and found them to be an important tool for consultation.

The new accommodation provides additional facilities for the school. The first phase of the project consists of a new building containing three design technology studios, a machine section and storage, as well as a section for student services, which is integrated into the school's main entry and security system.

A new covered walkway runs along the length of the new building, forming the school's main external route. The south-facing windows to the design and technology studios are under the canopy which creates a successful interaction between inside and out. Six timber-clad rooflights project from the sedum roof. The building is a high thermal mass structure served by a combination of natural and assisted ventilation with heat recovery.

The creation of the new design and technology studios has released classrooms in the existing school building, which will be refurbished to form comfortable and spacious general teaching spaces. A second block for drama and media studies is currently under construction.

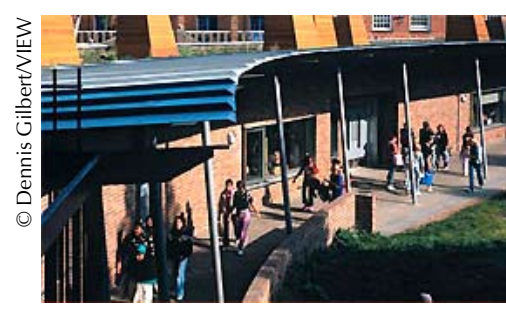

\section{FUNCTIONALITY - ACCESS}

Student movement has been rationalised to the single covered walkway, forming a unifying, fully accessible element between the school's mixed age buildings.

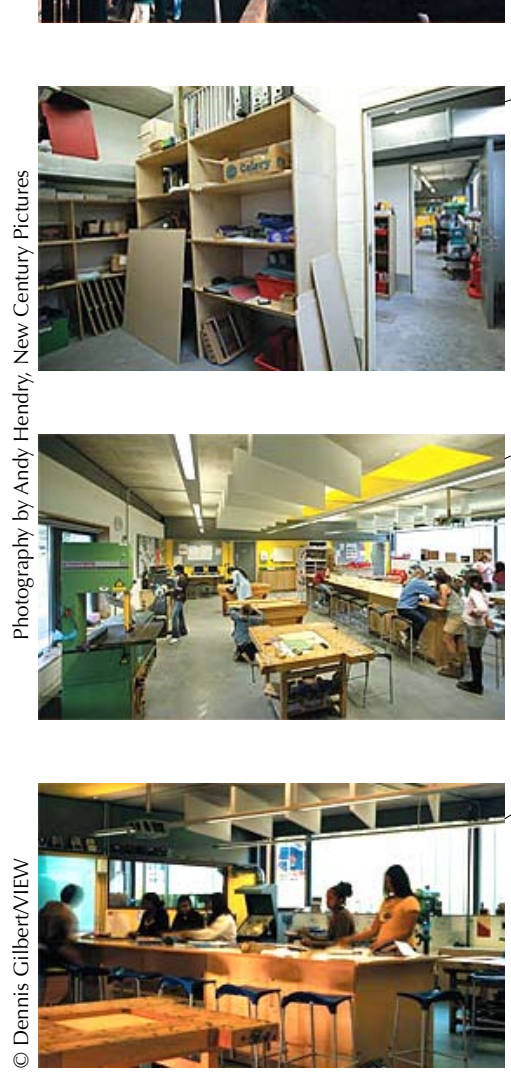

FUNCTIONALITY - USES

The new building structure allows for flexibility of the internal accommodation as the needs of the curriculum change in the future. The absence of internal columns affords flexibility in the configuration of the walls and division of space.

\section{BUILD QUALITY - PERFORMANCE}

A limited palette of hard-wearing materials gives an uncluttered, industrial feel to the design and technology studios. Painted blockwork walls, exposed concrete soffits and industrial floors offer easily maintained, durable surfaces.

\section{IMPACT - WITHIN THE SCHOOL}

Care has been taken to ensure that the building performs well acoustically. The innovative use of baffles, supported from the concrete soffits, allows for acoustic absorption within each studio.

1. Excerpt from "Picturing School Design: A Visual Guide to Secondary School Buildings and Their Surroundings Using the Design Quality Indicator for Schools", Commission for Architecture and the Built Environment, London, United Kingdom, 2005. 


\section{IMPACT - WITHIN THE SCHOOL。}

The desire for large, flexible, square studios has resulted in a relatively deep plan building. Windows and chimney-shaped rooflights provide the required natural lighting.
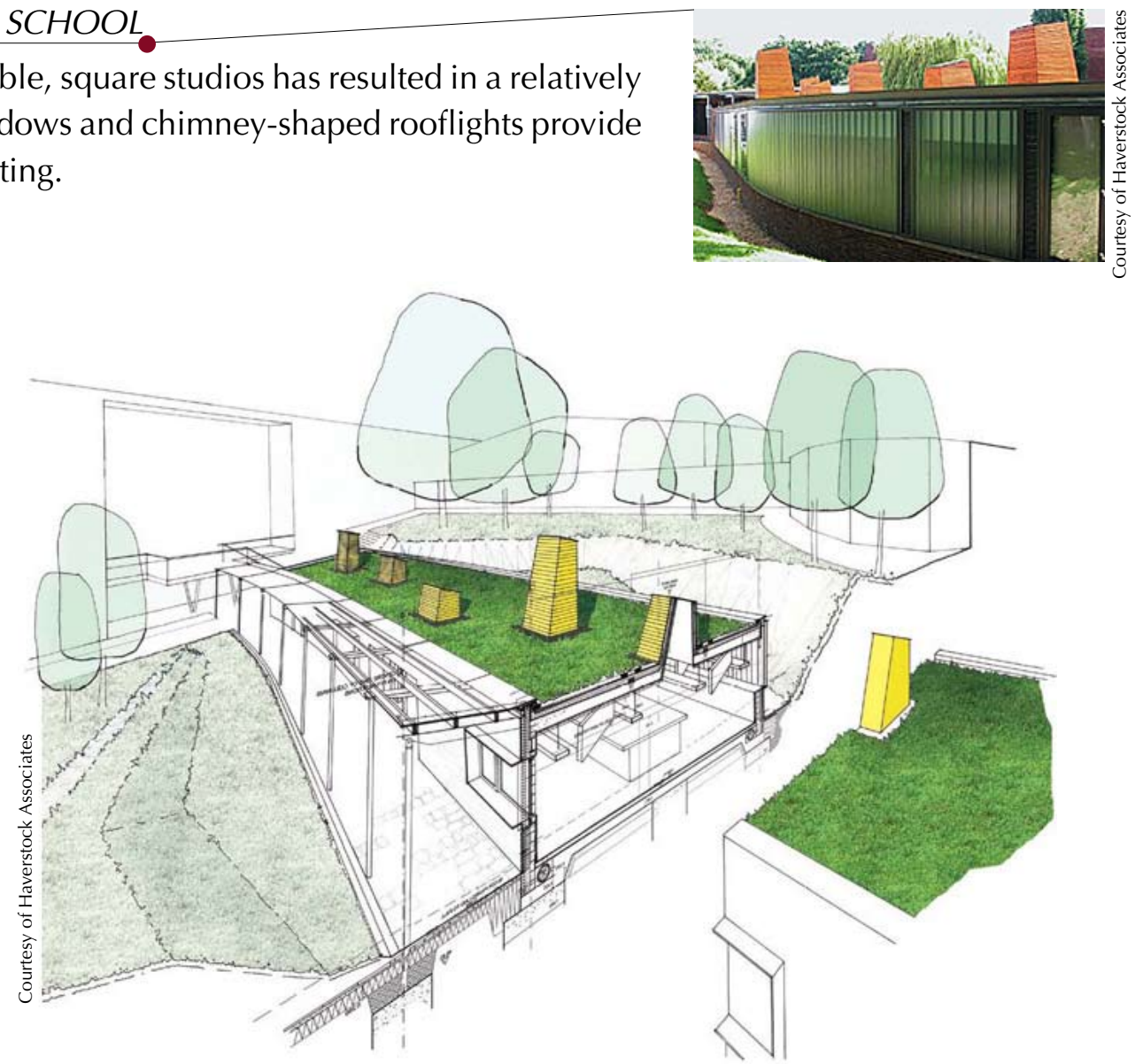

For further information about DQI for Schools, please consult www.dqi.org.uk/schools.

See www.oecd.org/edu/facilities/evaluatingquality for information about PEB's work on evaluating quality in educational facilities. 